\title{
A Study on the Influence of Teachers' Questioning in High School English Reading Class on Students' Critical Thinking
}

\author{
Wenjuan Song \\ School of Teacher Education, Shanxi Normal University, Shanxi, China
}

\begin{abstract}
This article studied whether teachers' questioning has an impact on the critical thinking of high school students in English class. Firstly, the author went to the practice school personally for a two-month classroom observation and recorded teachers' question in the classroom. This article referred to Bloom's taxonomy of educational objectives, and divided the cognitive process into six dimensions: Remember, Understand, Apply, Analyze, Evaluate, Create. The first two of the six types were primary cognitive problems, and the last four were advanced cognitive question. In order to analyze whether the questions help or improve the critical thinking of high school students, the author wrote down the number of each question asked and the proportion of the total number of questions. Then author gave the students questionnaires and interviewed teachers about relative questions. Based on the collected data, this article analyzed the correlation. This study showed a certain degree of positive correlation between the Teachers' questioning and the students' critical thinking scores through the classroom observation record table and the students' reading scores in the test, as well as the students' critical thinking questionnaire data.
\end{abstract}

Index Terms - teachers' questioning, critical thinking, high school English reading teaching

\section{INTRODUCTION}

Critical thinking, commonly known as speculative ability, can be traced back to Socrates' "elicitation teaching theory". In short, it is a way for people to deal with information and is a process of intellectual training. It involves a series of mental activities and cognitive processes that are difficult to quantify and describe in terms of language. Since American philosopher and educator, John Dewey, known as the "father of modern critical thinking," wrote in How We Think: "Reflection is positive, continuous, and a careful examination of the basis of any belief or assumption of the form of knowledge and the conclusions derived from it." This statement is recognized as the earliest definition of the concept of critical thinking. "The basic elements that make up critical thinking are claims, issues, and arguments. Identifying, analyzing, and evaluating these components are the key to critical thinking."In Western society, critical thinking ability is considered to be an important resource for individual citizens in private life and social life. The United States, the United Kingdom, Australia, New Zealand, Canada and other countries have listed the cultivation of speculative ability as one of the important tasks of higher education. In recent years, it has also been widely mentioned in China, and there are many related researches. Zhong Qiquan (2002) said that the era of knowledge economy is an era of advocating "critical thinking" because it is the main driving force for the advancement of the knowledge society. However, the study of "critical thinking" and "critical thinking teaching" in China is almost blank. This is incompatible with the principle of promoting "quality education." The "innovative spirit and practical ability" emphasized by "quality education", if left the teaching of "critical thinking", it will be an empty talk. However, there is little research on the critical thinking of middle school students, and there is room for further exploration.

Research scholars on teachers' questioning have also done a lot. Qiao Jinfang (2012) of Northeast Normal University said that one of the important methods for teachers guiding students to read is to ask students questions. Teachers' questioning is not only an important part of classroom teaching, but also the most common form of interaction between teachers and students in classroom teaching. Questioning provides an important source for students to input language, and provides opportunities for students to output language, and promotes interaction and communication between teachers and students, and even between students and students. Effective teacher questioning can stimulate students' participation awareness and help students better understand the text and develop students' ability to solve problems, so as to improve the teaching effect of reading class." The effectiveness of teachers' questioning and the interrelationships between various aspects were very detailed.

Most of the researches on English teaching and even classroom questioning and critical thinking focus on the study of college students. Professor Cheng Xiaotang (2015) proposed that English learning is conducive to the development of students' critical thinking ability. In English learning, it can be adopted. Guiding students to identify and analyze the attitudes of language response, implied meanings, and presets to develop students' critical thinking ability. Yu Hang (2016) talked about teachers' questioning that "Teachers' questioning can be designed by teachers based on the topic of the text. These questions are not fixed. It can inspire students to think boldly and express their opinions." Through 
questioning and answering, not only the students' critical thinking ability but also their speaking ability is cultivated." in her "College English Teaching and the Cultivation of Students' Critical Thinking Ability". Yang Lifang (2015) of Beijing Foreign Language University discussed the role of waveform questioning methods in the development of the thinking ability of English majors. There is not much research on middle school students. We need to continue to deepen and discover more deep connections. We will take corresponding measures in practical teaching to help middle school students learn better and cultivate critical thinking. According to Piaget's cognitive development theory, the formal computing stage (11-15 years old), children at this stage form logical thinking to solve various problems, from the specific image of the previous stage to the abstract reasoning. At this stage children can already start the hypothetical scenario.(Dong Jinping, 2015). During the youth period, all kinds of thinking have made great progress and development. At the critical stage of human thinking development, it is worthwhile to study and discover, so as to put forward better suggestions and help them to grow better. However, in China, English teaching of the most middle school still focus on the acquisition and teaching of English language knowledge. Vocabulary, grammar and reading are still the most important things and the cultivation of students' critical thinking skills are ignored. Because high school is at a critical stage of life growth, critical thinking is also in an important period of development, so it must be paid attention to and cultivated to promote the optimal development of individuals.

\section{MethodOLOGY}

This study aims to answer the following questions:

1. What is the tendency of high school students to think critically?

2. What is the use of teachers' questioning in the middle school English class? Through the class record table [(1) the type of questions the teacher asks in the class; (2) the number of questions asked by each question, the proportion of questions; the total number of questions; (3) whether the question is targeted, inspiring; )

3. What is the relationship between the teacher's questioning situation and the critical thinking tendency of high school students (English scores, reading grades)?

In this article, the author went to the Experimental School of Shanxi Normal University where she was in the internship school and followed eight high school teachers for two months to do classroom observation. The author mainly observed the types of teachers' questioning and their proportions, and interviewed 8 teachers. In addition, 384 high school students were selected as subjects for questionnaires and reading ability tests. The English of these high school students is at the general level of the city and is more representative. Eight teachers are also ordinary teachers. The students were from class 299, 300, 302, 303, 305, 307, 309, and 310, with a total of 50, 47, 44, 52, 41, 45, 52, and 53 people. It mainly investigates students' critical thinking tendency, and compares the English test scores of eight classes in October, especially reading grades, in order to explore the relationship between the two items.

The research methods mainly used in this study are: literature method, classroom observation method, questionnaire survey method, test method and interview method. The most important ones are classroom observation method, questionnaire method and test method. The classroom observation method is to analyze teachers' questioning situation of the eight classes English reading class in the Experimental Middle School of Shanxi Normal University. The questionnaire method and the test method respectively analyze the relationship between teachers' questioning and students' critical thinking tendency in high school English reading teaching through questionnaire and English month test paper. The author used two months to attend classes in the school, observe the classroom, and do the classroom recording of each lesson by doing lecture notes and mobile phone recording. At the end of the month, the student's monthly test scores, especially the scores of the reading part, are used to observe how the teacher's questioning situation of different teachers affects the students' reading performance. This article uses Lu Ziwen and the Critical Thinking Survey (Chinese version) questionnaire presented by the California Critical Thinking Tendency Test (CCTDI) to study the critical thinking scores of students. The questionnaire is divided into seven parts. They are seeking truth, open thought, analytical ability, systematic ability, self-confidence, curiosity, and cognitive maturity of critical thinking (Lu Ziwen, 2010). Each part has ten questions, each setting has six degrees of discrimination, 1=very agree, $2=$ quite agree, $3=$ compared, 4=general approval, 5=quite disapproval, $6=$ very disagree, representing one to six points respectively. The results are used to analyze the current state of critical thinking among high school students, the horizontal and vertical comparisons between dimensions, and how teachers' questioning relate to them.

First of all, the author selects eight high school teachers to number as T1, T2....T8 in the internship school. And then followed each teacher for one week (10 lessons), observed their class and wrote down the class observes table, recorded the information you needed. In addition, the author interviewed the eight teachers during the spare time after class. The author had five questions asked the eight teachers, and made a record about teachers' opinions. The author recorded students' monthly test scores in October, especially in the reading section, comparing different classes that existing differences. And then the author gave out questionnaires of critical thinking for students which calculating the scores of each student, comparing the average scores of each class, and using SPSS 21 to do data analysis in order to find out the relevance of teachers' questioning, reading scores and critical thinking tendencies.

\section{RESULTS AND ANALYSIS}




\section{A. Results and Discussion of Teacher Questions (Analysis of Classroom Observation Survey Results, Analysis of Interview Results)}

In this study, eight English teachers and eight classes students from a high school English group in Linfen City were selected for a two-month classroom observation, and the teaching of reading lessons for each English-speaking teacher was observed. The author selected a same subject teaching unit of the eight English teachers (six lessons), unit3 Travel Journal, and conducted an analysis according to the classroom observation project table.

Studies have shown that the primary cognitive problems accounted for more than $70 \%$ of the questions asked by the eight teachers. In the reading class, the teachers' questioning is about basic knowledge, including vocabulary, grammar knowledge and reading. These all help students understand the basic content of the text, the frame of the reading text body, and the analysis of the components of the long and difficult sentences. After reading class, there will be a small part of the analysis about the text content, topic and evaluation of the subject. Students can put forward their own views in the class and come to exchange, discuss with teachers and classmates, crash sparks of thinking. The results of the questionnaire indicated that there were many high-level questions in the teacher's class, and the corresponding critical thinking scores of the students in the class were slightly higher. The primary question with less overall questions and the questioning had a larger proportion of the class, and the students' critical thinking scores were also average. This preliminary indicated that the teacher's questioning type and the student's critical thinking were positively related. It can be seen that the problem of high-level cognition in the teacher's class helped to cultivate students' critical thinking.

In order to gain a deeper understanding of the teacher's questioning behavior and purpose, the author interviewed with the teacher after the class observation and discovered that teachers' attitudes and opinions on questions directly affect whether they will reasonably set high-level questions to ask students through interview surveys and teachers' personal information. For the first question, "What do you think about the teachers' questioning in the English reading class?" T1...T8 teachers all believed that teachers' classroom questions were important and essential classroom links. First of all, the role of the teacher's questioning was affirmed on a macro level, and then the specific functions of the teacher's question were recorded from the details. The second question "Do you think that the teacher's question has an impact on the students' reading ability in the reading class?" All teachers thought that the questions in the class had a great influence on the students' reading ability. And appropriate in-depth questions can stimulate students to think. So for the types of questions studied in this paper, the primary questions can be used to detect the degree of knowledge of students, the familiarity with the textbook content and the mastery of the grammar vocabulary of the knowledge points in this section, and the higher leveled questions can encourage students to be active and think about evaluation and promote the development of students' critical thinking.

At the same time, the reading scores of the students' monthly test paper scores are also more obvious. The scores of high-level questions teachers asked more and more interactive reading comprehension classes are higher than the ones that teachers less likely to ask questions or ask for higher grade cognitive questions. That explains that teachers' high-level questions can help students to improve their reading comprehension and critical thinking skills.

\section{B. Analysis and Discussion of the Investigation Results of Critical Thinking}

In this paper, the author drew on the Chinese version of the Critical Thinking Questionnaire (Lu Ziwen, 2010) written by CZDI2000, referring to Ran Yun of Chongqing Normal University, to investigate the current situation of critical thinking of high school students. The critical thinking questionnaire is divided into seven modules: search for truth, open mind, analytical ability, systematic ability, self-confidence, curiosity, and cognitive maturity of critical thinking (Lu Ziwen, 2010). Each module has ten questions, and each question has six degrees of discrimination, representing one to six points.

There are some about evaluation of the critical thinking ability of high school students. That are studies (Wang Kuanming of Guizhou Normal University, Ran Yun of Chongqing Normal University, etc.) that the scores of less than 210 points indicates that the subject's critical thinking ability is very weak or indicates the subject's thinking tendency is seriously opposed to critical thinking. Scores of 210-280 points indicates that the subject's critical thinking ability is weak or that the critical thinking tendency is in contradiction. Scores between 280-350 indicates that the subject's critical thinking ability is strong or that the subject maintains a positive attitude towards critical thinking. Those students whose scores reach or exceed 350 points indicating that the subject's critical thinking ability is very strong or indicates the subject's critical thinking tends to be stronger. According to the final data of the questionnaire, the critical thinking ability of high school students was generally weak. Most students, more than $80 \%$ of students had a critical thinking ability scores of less than 280 points. Each individual dimension is considered as 40 critical points to judge the positive and negative tendencies of critical thinking. A score of 30 or less indicates that critical thinking is contrary to some critical thinking tendency in the scale. In the 30-40 points, the subject is contradictory to the thinking tendency. At 40-50 the scores indicate that the subjects have a positive attitude towards this aspect of critical thinking. Those above 50 points indicate that the subject has a strong tendency to critical thinking (Lu Ziwen, 2010).

In the study of this paper, less than 210 students accounted for $10 \%$ of all students, their thinking tendency was opposite to critical thinking. Most students hold the thinking tendency mainly concentrated in 210-280 points, accounting for $64.8 \%$, and explained that their critical thinking is contradictory and not strong enough. Only $25.2 \%$ of students had a critical thinking ability at 280-350, they were positively positive about critical thinking. No more than 
350 students, that is to say there were no students with a strong tendency to think critically. This result indicated that the critical thinking ability of high school students was not very mature.

According to this judgment criterion, it also reflected the negative tendency of students in critical thinking such as analytical ability, self-confidence of critical thinking and curiosity from the analysis of the proportion of the figures in the critical thinking of this study. It also confirmed that the point mentioned by the teacher in the interview was that the students were not confident. They would come up with different opinions, but they would be convinced by others soon because they were uncertain or no confidence in their content, so they would change their mind soon and couldn't stick to themselves. As for the reasons that may cause this result, the author puts forward the hypothesis that the teacher may lack the training of the critical thinking of the students in the usual classroom, the lack of interaction with the students when asking questions, and the appropriate encouragement and affirmation.

\section{Discussion on the Correlation between Teacher Question Type and Critical Thinking}

In the research of Tian Qing of Si chuan Normal University, it was concluded that there was a significant correlation between different types of teachers' questions and students' critical thinking; high and low cognitive level questions and their six types of teachers' questions and students' critical thinking tendencies and each of its dimensions had different correlations. In the study of Shen Ping of the School of Foreign Languages at Kaili College, it was also pointed out that these were related to critical thinking ability according to Bloom's classification. The author conducted in-depth interviews with students based on these four types of questions. Through the analysis of the interview data, Shen Ping found that most of the students believed that the problems raised by the teachers in the higher-level cognitive field were too few, which was not conducive to the improvement of their critical thinking. It can be seen that the conclusions drawn by the above researchers were not only in their region, but also applicable to us. From many related studies, it can be inferred that the general situation of English teaching in primary and secondary schools in China and the critical thinking of students should be almost the same.

In this study, we can see from the classroom observation table, the critical thinking questionnaire and the scores of the students' monthly test paper readings that there were many high-level questions in the teacher's class, the reading scores in the test paper were higher, and the students' critical thinking scores were higher. It can be preliminary speculated that there was a certain degree of positive correlation between them. Of course, a student's high scores and high critical thinking scores were formed by the long-term effects of many factors. However, this paper only studies whether teachers' teacher questioning and students' critical thinking have a relationship. The conclusion can be established and the final result presented a certain degree of positive correlation.

\section{CONCLUSIONS AND SUGGESTIONS}

Finally, the results of this study showed that teachers' questioning and critical thinking do have a positive correlation. Students' critical thinking scores are higher and critical thinking is stronger if teachers ask high-level cognition questions, targeted and instructive questions. Therefore, the author puts forward some suggestions. The author hopes that teachers can strengthen their professional quality learning, improve their theoretical understanding, pay attention to the frontier dynamics of English teaching research, and actively learn the strategies of asking questions. At the same time, they can pay attention to the individual differences of students and rationally set up efficient problems. On the basis of completing teaching tasks, teachers can help to develop students' critical thinking ability. Meanwhile, the school can also provide opportunities for teachers for further study, help them to make progress, introduce excellent teachers, and go out to learn advanced teaching methods. Schools and teachers should work together to help students learn to think and train their critical thinking skills.

\section{REFERENCES}

[1] Dewey, J. (1933). How We Think: A Restatement of the Reflective Thinking to the Educative Process. Boston: Health \& Company

[2] Dong Jinping. (2015). The Revelation of Piaget's Cognitive Developmental Theory in Language Education. Journal of Qiqihar University (Phi \& Soc Sci), 1,178-179.

[3] Gao Zhiyan. (2017).The cultivation of critical thinking--On the role of teachers in the speculative teaching of English majors. Shaanxi Education (Higher education), 11, 17-19.

[4] Liu Ying. (2016). A Study on Teacher Questing Types of English Reading and Critical Reading Ability of Students in Junior High School. Yan Bian University.

[5] Lorin, W. Anderson \&David R. Krathwohl (et al.) (2009). A Taxonomy for learning, Teaching, and Assessing-A Revision of Bloom's Taxonomy of Educational Objectives. Beijing: Foreign Language Teaching and Research Press.

[6] Lu Ziwen. (2010). http://blog.sina.com.cn/s/blog-4b0f72620102e2el.htm.

[7] Qiao Jinfang. (2012). An Investigation into teacher questioning in English Reading Class of a Junior High School. Northeast Normal University.

[8] Ran Yun. (2016). A Study of Improving Critical Thinking by Classroom Questioning: A Case Study of English Reading Teaching in Senior High School. Chongqing Normal University.

[9] Shen Ping. (2014). Case Study of Teacher Questioning Behavior and Students Critical thinking in the College Reading Classroom. Science Teaching (Curriculum Teaching), 10, 106-107. DOI:10.16400/j.cnki.kjdkz.2014.10.035. 
[10] Tian Qing. (2018). A Study on the Correlation of Teacher Questions and Students' Critical Thinking Cultivation in Senior High English Reading Classes. Si Chuan Normal University.

[11] Wang Kuanming. (2016). An Investigation on the Status Quo of Critical Thinking Ability of Senior Middle School Students. Journal of Educational Development (Moral education and psychology), 12, 42-45.

[12] Yang Lifang. (2015). Cognitive Characteristics of Reading Teachers' Questioning and Cultivation of Thinking Ability. Foreign Languages in China. Vol.12 No.2 (General Serial 64), 68-79.

[13] Yu Hang. (2017). College English Teaching and the Cultivation of Students' Critical Thinking Ability. Science \& Technology Industry Parks, 4, 71-73+76.

[14] Zhong Qiquan. (2002). "Critical Thinking" and its teaching. Global Education. VOL.31.NO.1. 34-38.

Wenjuan Song was born in Shanxi province, China in 1992. She majored in English (translation) while undergraduate. She has received her bachelor's degree in 2016.

She is currently pursuing a master's degree in education at Shanxi Normal University and majoring in curriculum and teaching methodology (English). She mainly studies English teaching and development. She will graduate soon in 2019.

Song wenjuan is a part-time English teacher at the School of Modern Arts and Sciences, Shanxi Normal University. 